flows and their variations. An excellent start was made with the Surface Water Year Book (1938), further publication of which was unfortunately suspended by the War. To this brief indication of recent efforts to collect and utilize information regarding the water resources of Great Britain, there should be added the contributions concerning underground water made over a much longer period by the Geologi. cal Survey in general memoirs and maps, in special water-supply memoirs, and since 1939 in its Wartime Pamphlets.

A fair picture is given by the White Paper of the existing chaos of water legislation and organization, with Parliament as the sole authority able to empower the taking of surface supplies (representing about three-quarters of the total), and the Ministry of Health practically responsible for underground supplies, but without adequate powers. Actual undertakings are in charge of far more than a thousand authorities, public and private, statutory and nonstatutory, dealing with quantities which vary from a few thousand gallons a day to the 300 million gallons a day of the Metropolitan Water Board. Many Government departments have varying degrees of interest in water and rights of control or comment. Yet it still remains true that the private owner of land in Great Britain has unrestricted rights to do what he pleases with any quantity of water he can extract from the ground.

The White Paper proposes the revision of the general law governing water supplies (the out-of-date Waterworks Clauses Acts of 1847 and 1863), and the simplification and co-ordination of the means for their provision and control. Some progress in the first has already been made with the Waterworks Undertakings Bill of 1943. For the latter, the White Paper proposes machinery which may work well enough, given goodwill and understanding all round, but which is certainly open to the criticism of being unnecessarily complicated. The general argument on which the proposals are based, that change is undesirable unless it will lead to improvement, leads properly to the conclusion that existing water authorities should not be disturbed so long as they are providing efficient and economic service, But it does not necessarily follow that the rather haphazard group of bodies concerned with the investigation and general control of water and water-supplies should also be preserved.

The most vital proposal is that all general control should be centred in the Minister of Health, with appeal to Parliament only in cases in which matters of major policy or public interest may be concerned. The Minister is to be given wide powers to promote and authorize the provision of supplies, to require amalgamation of uhdertakings, to survey their efficiency, to protect resources, and to require information from users and sinkers. $\mathrm{He}$ is to be advised on general policy by a further reconstituted central advisory committee, made statutory; and on local matters by the regional committees, also reconstituted and increased in number. The investigations of the Inland Water Survey are to be promoted, and further information as to needs and supplies is to be obtained through the Ministries of Agriculture and Fisheries and of Town and Country Planning. Reference to the important geological aspects of the matter are somewhat vague. The valuable work of the Geological Survey is acknowledged and a summary of those aspects, contributed by the Survey, is included as an appendix. It is stated that the Survey will be "mainly responsible" for the provision of information regarding underground resources, though the Inland Water Survey is charged with collecting the same data. The matter is further complicated by the proposal, excellent in itself, to set up twenty-nine river boards with broad powers for the general care and supervision of riversystems. But among the duties assigned to them is the regular gauging of rivers, which is the main purpose for which the Inland Water Survey was instituted. It is indeed a little bewildering to contemplate the number of separate authorities to which the same data may have to be returned, unless very careful co-ordination is maintained.

While these incidental comments on detail suggest that the scheme is not fully matured, there can be no question of the value of the White Paper as a whole. Perhaps the most serious reflexion which will occur to the careful reader will concern the magnitude and complexity of the whole question, and a doubt whether it should be dealt with by a section of a Government department primarily concerned with quite different matters. There is much to be said for the proposal virtually common to the pamphlet of the Institution of Water Engineers and the Labour Party's "PostWar Water Policy", that there should be a "permanent Statutory Authority . . . analogous to the Electricity Commission" or a "National Water Commission". No single service is of greater moment to the nation than its water, nor does any make a greater demand for expert control.

\section{SCIENTIFIC RESEARCH IN BRITISH UNIVERSITIES}

$\mathrm{E}^{\mathrm{s}}$ VERY scientific worker will acclaim the example to British industry which has been set by the directors of Imperial Chemical Industries, Ltd., in providing for eighty fellowships at nine universities in Great Britain to be held by senior workers in certain sciences. The need for provision of this kind has been repeatedly stressed in various reports and papers on scientific and industrial research ; for example, those from the Parliamentary and Scientific Committee and the London Chamber of Commerce, and in the more recent statement from Nuffield College. The debate had reached a point at which action was clearly called for, and in the scheme which is now announced, the directors of Imperial Chemical Industries, who had obviously been following the debate closely, have given a timely lead.

Study of the scheme indicates that its terms are as admirable as its generosity, and Lord McGowan's letter to the chancellors of the universities also testifies to the careful consideration which he and his 
colleagues have given to the question in all its aspects. There is no confusion here between the strategy and the tactics of research. The main purpose of the scheme is to strengthen the general provision in British universities for scientific teaching and research. It is a concrete reaffirmation of the opinion so strongly emphasized in the recent report on the extension of scientific research in the University of Manchester, particularly in relation to the industries of its area, as to the relation between teaching standards and research and between industry and the universities-a report which, it will be noted, has already been endorsed by Dr. C. J. T. Cronshaw, one of the directors of Imperial Chemical Industries. As Lord McGowan's letter puts it: "Nearly three generations of experience of the administration and conduct of research have convinced us that academic and industrial research are interdependent and complementary, and that it is useless to expect substantial advances in industry without corresponding advances in academic science".

The relation between industrial and academic research could scarcely be better expressed, and the scheme encourages further the relations between teaching and research which should help to meet some recent criticism in this respect. Again, the point that in the strategy of research the first essential is to obtain men of the requisite ability is well seen in the hope of the directors of Imperial Chemical Industries that this policy, with wise selection of men as regards capabilities and tenure of office, will lead to the emergence of a body of men capable of taking high academic or industrial positions, thereby advancing academic and industrial research. If in fact such leaders are forthcoming-and there is no reason for doubting that they will be-there need be no fear that the correct tactics of research will not be devised or employed.

In seeking to strengthen the university scientific departments in whatever way each university thinks fit, the scheme makes the one prescription that the subjects of research should be "in chemistry or physics or in an allied science which has some direct relation to the manufacturing interests of Imperial Chemical Industries, Ltd., such, for example, as physical chemistry, biochemistry, colloid science, chemotherapy, pharmacology, engineering, or metallurgy". That prescription is broad enough to cover the whole scientific background of modern industry. Moreover, the universities to which this offer has been made have been selected on account of their size or metropolitan character or their geographic relation to the main centres of the Company's production. The challenge to the fuel, the metallurgical and the Yorkshire textile industries implied in the omission of the Universities of Leeds, Sheffield and Wales is unmistakable.

Only the most carping criticism could object that the scheme may further weight the balance of research in the universities in favour of the physical as against the biological or social sciences. Lord McGowan's letter indicates that nothing could be further from the minds of himself and his fellow directors in putting forward the scheme: it is rather their hope that it will be used by the universities to improve the balance of research effort, either in a particular university or between one university and another. It is difficult to conceive of a scheme better designed to safeguard the freedom of the universities in every way while encouraging the co-operation required to facilitate any redistribution of their research effort in accordance with a broad programme based on national needs. It will not escape notice that among the subjects of research enumerated are included some to which Sir Ernest Simon and others have already directed attention with the view of eliminating redundancy, promoting the effective development of existing schools and the provision of new schools to fill recognized gaps, through university consultation and co-operation.

The evidence of close and wise thinking which characterizes the whole scheme should commend it unreservedly to scientific workers. It is hard to imagine a scheme which could provide a more stimulating example to British industry and more practical encouragement to the scientific work of the universities, while avoiding any interference with their freedom of work; or at the same time provide for immediate action without prejudice to the large questions of strategy which are still being debated.

On the heels of this statement from Imperial Chemical Industries, Ltd., on research comes the announcement from the Bank of England that it is setting aside $£ 100,000$ for the establishment of a trust fund for the promotion of economic research (see p. 175 of this issue). In this case the trust will award fellowships, and there is no stipulation that the research is to be carried out in university institutions ; but there is little doubt that the universities will benefit from the increased facilities for research in economics. Chemical industry and high finance have thus endorsed the claims of research : it is surely not too much to expect that the example they have set will be studied carefully-and acted upon-by industry in general.

\section{MINING AND MINERS}

The History of Miners' Diseases

A Medical and Social Interpretation. By Dr. George Rosen. Pp. xii $+490+17$ plates. (New York: Schuman's, 1943.) 8.50 dollars.

THIS history covers a wide field. Part 1 begins with neolithic times, when the flint miners apparently suffered from silicosis, which is hence the oldest known oceupational disease. The author then discusses the mining situation during the Middle Ages and the Renaissance, and finally reviews the investigation of miners' diseases during the seventeenth and eighteenth centuries. Part 2, which forms the bulk of the work, is confined to the nineteenth century, and deals with mining and miners, the diseases of -miners, and the beginnings of social and protective legislation. Most of the important work on these subjects, however, belongs to the twentieth century, and we endorse the hope expressed by Prof. Sigerist in his introduction that the author will now write a second volume in which the history of the last fifty years will be discussed. 